\title{
US research put to vote
}

\section{Washington}

A STATUTE that would ban nuclear weapons research in the city of Cambridge, Massachusetts, has been put forward by anti-nuclear groups and will be decided at a referendum in November. If the proposed act is passed and then made to stick, the city of Cambridge would be compelled to fine or imprison individuals defying the prohibition. As well as Harvard University and the Massachusetts Institute of Technology (MIT), the city of Cambridge includes within its boundaries one of the leading nuclear weapons laboratories in the United States, the Charles Stark Draper Laboratory, now strictly independent of MIT, which previously gave it shelter.

The unprecedented statute, drafted by a local anti-nuclear group called Mobilization for Survival, raises far-reaching constitutional issues and is being regarded as a grave threat by the Draper Laboratory, which devotes the bulk of its research to the development of guidance and control systems for American ballistic missiles. Lawyers for both sides were expected to appear before the Massachusetts supreme court this week to decide whether the act, which has already been supported by the required number of signatures, is to be allowed to appear on the November ballot.

Under city law, referendum questions supported by a petition signed by more than 4,500 voters can be added to the ballot papers in the biennial election for city councillors. Mobilization for Survival, which has gathered more signatures than it

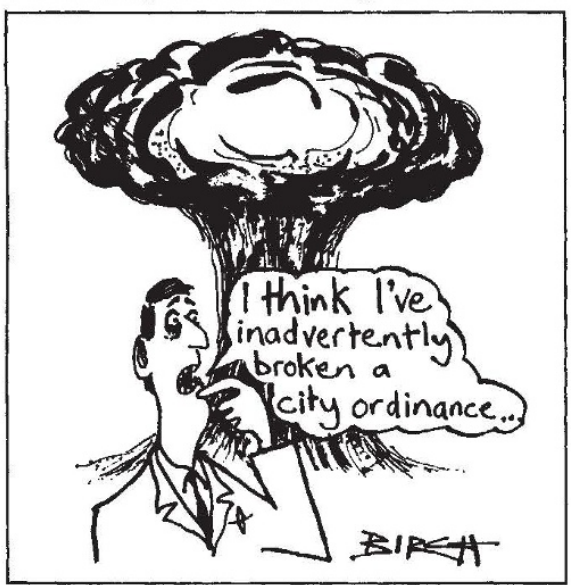

needs, is asking the supreme court to force the council to put the act on the ballot: at an earlier meeting the council had been unable to decide what to do about the petition.

Joseph O'Connor, vice president for administration at Draper, said the laboratory believed the act would be challenged on constitutional grounds because it was an encroachment on intellectual freedom and attempted to force a city government to thwart nationally determined policies. If it were passed, the bulk of the work conducted at the laboratory, which employs 1,800 staff and spends about $\$ 140$ million a year, would be classified as illegal.

Several towns without any nuclear facilities have this year declared themselves "nuclear-free zones", and a non-binding call to prohibit nuclear weapons research was supported by 74 per cent of Cambridge voters in a referendum last year. But the new measure, the Nuclear-Free Cambridge Act, is the first attempt by the anti-nuclear movement to force a city council to outlaw existing facilities.

Under the act no person, university, corporation, laboratory or other institution would be allowed after October 1985 to engage in any work related to the research, development, testing, transportation or disposal of nuclear weapons or their components. A violation of the act would be punishable by up to 60 days in prison or a fine of up to $\$ 5,000$. Basic research whose "primary purpose" is not to produce nuclear weapons is explicitly exempted, as is nuclear medicine and the use of fissionable materials for smoke detectors and other peaceful purposes.

Neither Harvard nor MIT has yet taken a formal position on the referendum. Spokesmen for both institutions said they had been advised that the act would not affect them since they already prohibit classified research. Individuals at both institutions have nevertheless joined in the controversy on both sides. Ernest May, professor of government at Harvard, is chairman of a group called Citizens Against Research Bans which opposes the statute.

Unlike earlier versions of similar legislation proposed elsewhere in the United States, the Cambridge act contains a section giving its justification for the measure. Weapons research, it says, makes Cambridge a prime target in a nuclear war and brings with it an "undesired security appartus" that threatens civil liberties. In adopting the ordinance, it adds, Cambridge citizens would end their "complicity" with preparations for nuclear war. Peter David

\section{Three Mile Island}

\section{Damage to core revealed}

\section{Washington}

SONAR mapping of the interior at Three Mile Island last week has shown that the 1979 accident caused more extensive damage than earlier believed to the fuel core of the reactor. Virtually the whole surface of the core appears to have collapsed into a bed of rubble, leaving a void five feet deep and dimming remaining hopes that some of the fuel assemblies had survived intact and could be removed in one piece.

Engineers have known since making a "quick look" television inspection of the core last year that upper portions had collapsed, but did not believe that the damage extended across the whole area. The results of sonar mapping now suggest that the void extends virtually to the edge of the core and that there are unlikely to be any assemblies intact.

The discovery will put a further wrinkle in the $\$ 1,000$ million recovery effort, but may not provide any new insights into the accident itself. Site engineers say that the evidence of extensive damage could indicate that temperatures in the core had reached a higher level than hitherto estimated, but insist that there is still no sign that any fuel melted.

Further light may, however, be shed on the accident after analysis of the first sample of debris from the core, removed last week for shipping to the Department of Energy's National Engineering Laboratory in Idaho. The one-cubic-inch sample was brought to the surface by technicians using a steel scoop attached to a 45-foot rod. Unshielded, the sample would have exposed the technicians to a dose of $3 \mathrm{rem}$ an hour. A total of six samples are to be removed from the core to help planners decide how to design the tools needed to defuel the reactor.

The General Public Utilities Corporation (GPU), the reactor's owner, hopes to begin defuelling the core in March 1985 and to restore the plant to a "normal radiological condition" by 1988 . Nearly a million gallons of radioactive water have already been removed from the plant and recent activities have concentrated on reducing radiation in the containment building - now down from 350 to 200 millirems per hour on the ground floor.

GPU hopes that the reactor head can be removed early next year and the plenum lifted off several months later. Rubble in the fuel core will be removed underwater into canisters in 1985 and 1986.

The Nuclear Regulatory Commission (NRC) is meanwhile showing no signs of acceding in the near future to GPU requests for permission to restart the undamaged Unit 1 reactor at Three Mile Island. Technical problems associated with Unit 1's steam generators are still unresolved and the commission is still considering charges that the utility's management lacks the integrity and competence needed to operate the reactor safely.

One commissioner, Victor Gilinsky, has already made it clear that he is not prepared to approve a Unit 1 restart until the top management of GPU has been replaced. In a memorandum last February, Gilinsky described GPU as a company whose management took a "narrow and grudging" view of its public responsibilities and sought to get by with the minimum, "be it in terms of plant equipment, staff discipline and training, or forthrightness with public authorities",

Peter David 